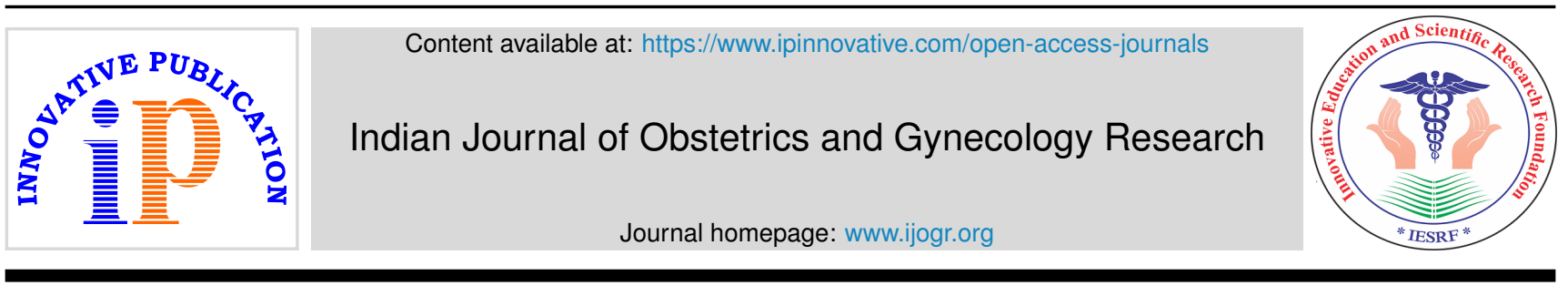

Original Research Article

\title{
To compare the diagnostic accuracy of hysteroscopy with transvaginal sonography in detection of endometrial polyp and endometrial hyperplasia in peri and postmenopausal women with abnormal uterine bleeding
}

\author{
Surbhi Sharma ${ }^{1, *}$, Anoop Sharma ${ }^{1}$ \\ ${ }^{1}$ Dept. of Obstetrics and Gynecology, Indira Gandhi Medical College \& Hospital, Shimla, Himachal Pradesh, India
}

\section{A R T I C L E I N F O}

Article history:

Received 29-08-2020

Accepted 11-09-2020

Available online 07-12-2020

\section{Keywords:}

Hysteroscopy

Transvaginal

Sonography

Endometrial polyp

\begin{abstract}
A B S T R A C T
Background: Abnormal uterine bleeding is the most common health problem encountered by women. AUB is a common gynaecological complaint and it may involve females at any age group. $33 \%$ of women referred to gynaecology clinics have AUB and the figure rises to $69 \%$ in premenopausal and postmenopausal women. Abnormal uterine bleeding accounts for two thirds of all hysterectomies.

Materials and Methods: The present study was prospective cross sectional study conducted in the Department of Obstetrics and Gynaecology, Kamla Nehru State Hospital for Mother \&Child Indira Gandhi Medical College Shimla for period of one year w.e.f 1st May 2018 to 30th April 2019. The study was started after hospital ethical committee approval.76 patients peri and post menopausal women were enrolled in the study after taking written consent).A detailed history, general and systemic examination was done. All patients underwent transvaginal sonography followed by hysteroscopy and further management was done according to the abnormality detected.

Results: Hyperplasia on TVS was present in 15 study subjects i.e 19.7\% (14 perimenopausal one postmenopausal). 13 subjects i.e $17.1 \%$ on hysteroscopy showed hyperplasia further on histopathology hyperplasia was confirmed in 15 subjects i.e $19.7 \%$ (14 had simple hyperplasia one had complex hyperplasia with atypia). On TVS endometrial polyp was seen in 22 subjects i.e $28.9 \%$ (18 perimenopausal four post menopausal) Hysteroscopy showed that 27 subjects i.e $35.5 \%$ had endometrial polyp (23 peri menopausal four postmenopausal). Further on histopathology endometrial polyp was confirmed to be present in 26 subjects i.e $34.2 \%$. Sensitivity Specificity PPV NPV of Transvaginal sonography versus hysteroscopy for endometrial polyp was $81.5 \% 100 \% 100 \%, 88.6 \%$ repectively. For endometrial hyperplasia Sensitivity Specificiy PPV NPV was 100\% 96.3\% 86.9\% 100\% respectively.

Conclusion: Abnormal uterine bleeding is a problem which women in perimenopausal and postmenopausal period frequently encounter. Of all investigations, TVS is quick, simple, painless, least invasive, less expensive and readily available procedure. Hysteroscopy not only allows direct visual observation of pathology but also provides a means to sample the site, most likely to yield positive results. Hence, it should be made an essential part of diagnostic workup of abnormal uterine bleeding.
\end{abstract}

(C) This is an open access article distributed under the terms of the Creative Commons Attribution License (https://creativecommons.org/licenses/by/4.0/) which permits unrestricted use, distribution, and reproduction in any medium, provided the original author and source are credited.

\section{Introduction}

Abnormal uterine bleeding is the most common health problem encountered by women. ${ }^{1}$ It is defined as bleeding from uterus that differs from that of usual normal menstrual bleeding, in frequency of occurrence or in amount or in

\footnotetext{
* Corresponding author.

E-mail address: surbhisharma2425@gmail.com (S. Sharma).
}

alteration of flow. ${ }^{1}$ AUB is a common gynaecological complaint and it may involve females at any age group. ${ }^{2}$ $33 \%$ of women referred to gynaecology clinics have AUB and the figure rises to $69 \%$ in premenopausal and postmenopausal women. ${ }^{2}$ Abnormal uterine bleeding accounts for two-thirds of all hysterectomies. ${ }^{3}$ Prior to menopause comes the perimenopausal transitional period 
that encompasses the change from normal ovulatory cycles to cessation of menses and is marked by irregularity of menstrual cycles. ${ }^{4 M e}$ nopause is defined as time of cessation of ovarian function resulting in permanent amenorrhoea for 1 year. ${ }^{5}$ However, vaginal bleeding occurring anytime after 6 months in menopausal age should be considered as postmenopausal bleeding and should be investigated. ${ }^{3}$ It normally occurs between ages of $45-50$ years, the average age being 47 years. ${ }^{5}$

Prevalence of AUB is around $17.9 \%$ in India. ${ }^{6}$ AUB in perimenopausal women demonstrated prevalence of normal endometrium (78.4\%), endometrial hyperplasia (11.8), polyp (4.2\%) and adenocarcinoma $(5.5 \%) .{ }^{7}$ Perimenopausal age group women may present with heavy menstrual bleeding, intermenstrual bleeding or contact bleeding whereas postmenopausal women may complain of spotting and heavy menstrual flow. ${ }^{8}$ Atrophic endometritis, endometrial hyperplasia, endometrial polyps, endometrial myomas\& endometrial cancers are leading causes of postmenopausal bleeding. ${ }^{9}$ About $80 \%$ of endometrial cancers in post-menopausal women occur in 50-65 years. ${ }^{7}$ On the other hand $10-15 \%$ of women with post-menopausal bleeding have endometrial cancers. ${ }^{9}$

Women report to gynaecologists whenever there is departure from their personal menstrual experiences. ${ }^{10}$ Variations from normal cyclical pattern in perimenopausal age group may be due to physiological hormonal changes on one hand or may be due to neoplastic changes either benign or malignant, on the other hand. ${ }^{10}$ Accurate diagnosis of causative factor of abnormal uterine bleeding in both the groups is of utmost importance, so that appropriate management can be established. ${ }^{10}$

Tests have evolved over the years starting from blind dilatation and curettage to latest immunohistochemical markers. ${ }^{11}$ Relative accuracy of these tests varies and gynaecologists all over the world up till now have not reached a consensus on what test to advise first. ${ }^{10}$

TVS examination of uterus in AUB woman is quick, simple, painless, less expensive and accurate procedure. ${ }^{11}$ Endometrial thickness shown by TVS can be interpreted as Secretory, Proliferative Endometrium or Abnormal Endometrium depending on the thickness measurement and co-relating it clinically with the phase of Menstruation. ${ }^{12}$

Ability of TVS for screening the lesions within the endometrial cavity is limited. The finding of a thickened central endometrial complex seen on TVS is often nonspecific and may be caused by an endometrial polyp, submucosal fibroids, endometrial hyperplasia, carcinoma, or cystic atrophy. Focal lesions are underdiagnosed at TVS because of limitations of the double-layer thickness evaluation. ${ }^{13}$

In hysteroscopy an endoscope, usually $3-5 \mathrm{~mm}$ is inserted into the endometrial cavity, uterine cavity is then visualized. ${ }^{8}$ The advantages of hysteroscopy as an accurate diagnostic technique are that it not only allows direct visual observation of pathology but also provides a means to sample the site, most likely to yield positive results. ${ }^{14}$ Also hysteroscopy can detect intracavitary lesions such as leiomyomas and polyps that might be missed on TVS or endometrial sampling. ${ }^{8}$ Commonly performed procedures utilizing hysteroscopy include diagnostic hysteroscopy, tubal sterilization, polypectomy myomectomy, and excision of uterine septa. Submucousmyomas no longer require hysterectomy because they can be satisfactorily managed conservatively by operative hysteroscopy. ${ }^{15}$ Hysteroscopic examination is superior to other methods in evaluation of endometrial cavity. It should not replace the histological diagnosis. Hysteroscopy is complementary to histological analysisas it permits pan evaluation of endometrial mucosa and biopsy is taken from abnormal areas in the same setting. ${ }^{16}$

\section{Materials and Methods}

The present study was prospective cross-sectional study conducted in the Department of Obstetrics and Gynaecology, Kamla Nehru State Hospital for Mother \& Child Indira Gandhi Medical College Shimla for period of one year w.e.f 1st May 2018 to 30th April 2019. The study was started after hospital ethical committee approval.76 patients $(\geq 40$ years and post menopausal women were enrolled in the study (after taking written consent). A detailed history, general and systemic examination was done. The study population was subjected to a thorough physical examination and routine investigations followed by transvaginal sonography and then by hysteroscopy after obtaining post-counselling informed consent. The procedure was performed in a minor operation theatre under sedation. Patient was taken to the procedure room and placed in the dorsal lithotomy position. After a bimanual examination, cervix was cleaned with using of $10 \%$ povidone-iodine or A single-toothed tenaculum was then applied to the anterior lip of the cervix. A small amount of local anaesthetic was used prior to applying the tenaculum.

Normal saline was used as the distension media. Once equipment for distention media was activated and functional, the flow of the medium was started. As the hysteroscope was introduced to the external cervical os and advanced into the endocervical canal, attention was turned to the video monitor or eyepiece. The distal tip of the hysteroscope was then gently advanced through the length of the cervix, taking care to keep the endocervical canal central on the viewing field when using a 0 degree scope. The first evaluation was done in panoramic view of the intrauterine cavity. Next, careful inspection of the following areas was done: lateral uterine walls, superior uterine cavity, and anterior and posterior uterine walls. Gentle movement of the hysteroscope was done during the 
procedure. Excessive trauma to the endometrial surface was avoided as it may cause bleeding which might obscure the view and has risk of perforation. Any pathology was inspected and documented.

Guided biopsy was taken and subjected to histopathological evaluation. Chi square test was applied to test the strength of association and $\mathrm{p}$ value less than 0.05 was considered significant. For quantitative data, mean and standard deviation was calculated and comparison will be done using student $\mathrm{T}$ test.

\subsection{Inclusion criteria}

Perimenopausal women age $>40 y e a r s$ with menorrhagia, menometrorhagia, polymenorrhea, intermenstrual bleeding, post coital bleeding, Post menopausal bleeding.

\subsection{Exclusion criteria}

Pregnancy, Woman taking hormonal replacement therapy, obvious cause of bleeding from cervix and vagina, woman with bleeding diathesis, woman on anticoagulant therapy, transvaginalsonography showing adenexal pathology.

\section{Result}

A total of 76 symptomatic perimenopausal and post menopausal women were included in the study at Department of Obstetrics and Gynaecology, Kamla Nehru State Hospital for Mother \& Child, Indira Gandhi Medical College Shimla over a period of one year.

\subsection{TVS findings}

\subsubsection{Transvaginal sonography (TVS) findings}

All the study subjects underwent TVS examination. Our study observed that endometrial polyp was detected in 22 subjects (28.9\%) (four in postmenopausal, 18 in perimenopausal AUB), hyperplasia was found in 15 subjects i.e $19.7 \%$. (14 perimenopausal one post menopausal)

Table 1:

\begin{tabular}{lcc}
\hline TVS Findings & N & Percentage \\
Polyp & 22 & $28.9 \%$ \\
ET Size $(\mathrm{mm})>12$ & 15 & $19.7 \%$ \\
\hline
\end{tabular}

Data expressed as frequency and percentage.

*On TVS many subjects had more than one finding.

\subsection{Hysteroscopy findings}

In the present study, on hysteroscopy endometrial hyperplasia was seen in 13 subjects (17.1\%), endometrial polyp was present in 27 subjects $(35.5 \%)$.
Table 2:

\begin{tabular}{lcc}
\hline Hysteroscopy Findings & n & Percentage \\
Hyperplasia & 13 & $17.1 \%$ \\
Endometrial Polyp & 27 & $35.5 \%$ \\
\hline
\end{tabular}

Hysteroscopy findings $(\mathrm{n}=76)$

\subsection{On histopathology}

In our study hyperplasia was present in 15 subjects (simple hyperplasia was present in 14 subjects, 1(1.3\%) had complex hyperplasia with atypia), endometrial polyp was detected in $26(34.2 \%)$.

Table 3: Histopathology examination

\begin{tabular}{lcc}
\hline Histopathology Findings & N & Percentage \\
Hyperplasia & 14 & $18.4 \%$ \\
Endometrial Polyp & 26 & $34.2 \%$ \\
\hline
\end{tabular}

Correlation of TVS hysteroscopy and histopathology

Table 4: Endometrial hyperplasia

\begin{tabular}{lccc}
\hline & TVS & Hysteroscopy & HPE \\
Peri & 14 & 12 & 14 \\
Post & 1 & 1 & 1 \\
Total & $19.7 \%$ & $17.1 \%$ & $19.7 \%$ \\
\hline
\end{tabular}

Hyperplasia on TVS was present in 15 study subjects i.e $19.7 \%$ (14 perimenopausal one postmenopausal). 13 subjects i.e $17.1 \%$ on hysteroscopy showed hyperplasia further on histopathology hyperplasia was confirmed in 15 subjects i.e 19.7\% (14 had simple hyperplasia one had complex hyperplasia with atypia).

2 cases of hyperplasia were misdiagnosed on hysteroscopy 1 as polyp and other as normal endometrium.

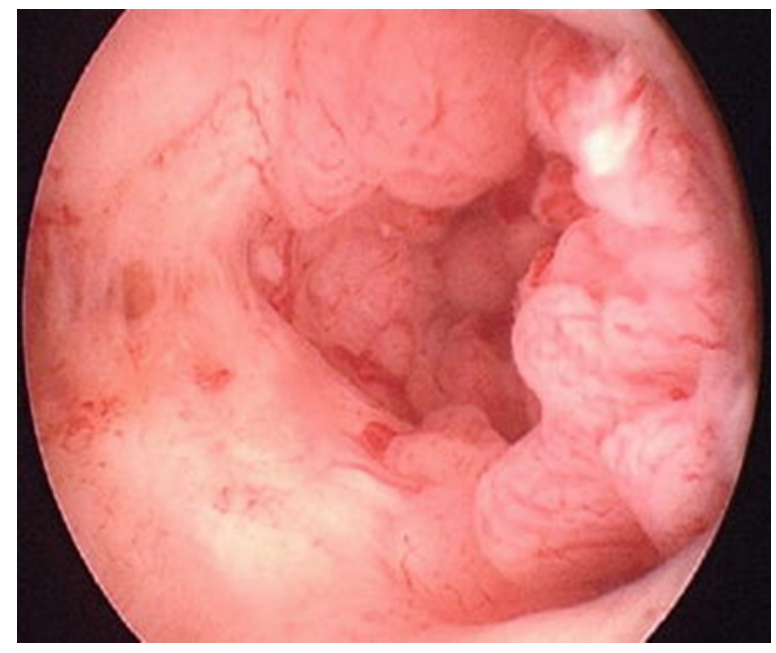

Fig. 1: 
Table 5: Endometrial polyp

\begin{tabular}{lccc}
\hline & TVS & Hysteroscopy & HPE \\
Peri & 18 & 23 & 22 \\
Post & 4 & 4 & 4 \\
Total & $28.9 \%$ & $35.5 \%$ & $34.2 \%$ \\
\hline
\end{tabular}

On TVS endometrial polyp was seen in 22 subjects i.e $28.9 \%$ (18 perimenopausal four post menopausal) Hysteroscopy showed that 27 subjects i.e $35.5 \%$ had endometrial polyp (23 peri menopausal four postmenopausal). Further on histopathology endometrial polyp was confirmed to be present in 26 subjects i.e $34.2 \%$.

TVS missed 4 cases of endometrial polyp as:

2 Subjects were misdiagnosed as hyperplasia, 1 as fibroid, 1 as normal.

On hysteroscopy 1 case of polyp was falsely diagnosed as hyperplasia.

Table 6: TVS versus hysteroscopy (Endometrial polyp)

\begin{tabular}{lccc}
\hline Sensitivity & Specificity & PPV & NPV \\
$81.5 \%$ & $100 \%$ & $100 \%$ & $88.6 \%$ \\
\hline
\end{tabular}

Table 7: TVS versus hysteroscopy (Endometrial hyperplasia)

\begin{tabular}{lccc}
\hline Sensitivity & Specificity & PPV & NPV \\
$100 \%$ & $96.3 \%$ & $86.6 \%$ & $100 \%$ \\
\hline
\end{tabular}

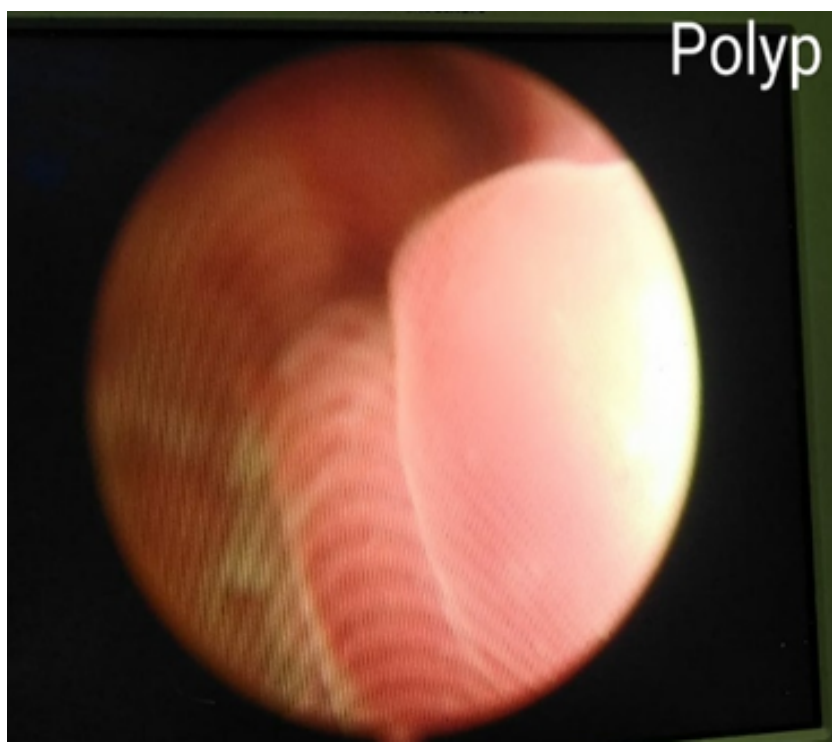

Fig. 2:

\section{Discussion}

Abnormal uterine bleeding is defined as bleeding from uterus that differs from that of usual normal menstrual bleeding, in frequency of occurrence or in amount or in alteration of flow. AUB is a common gynaecological complaint and it may involve females at any age. In the past, when few diagnostic options were available, this condition was routinely managed with uterine curettage. D \& $\mathrm{C}$ being a blind procedure can miss the specific lesions. However, with the addition of Transvaginal sonography, saline infusion sonography and hysteroscopy diagnostic accuracy has improved significantly. Office hysteroscopy has been shown to be a simple, safe, well tolerated and reliable procedure in the diagnosis of AUB across all age groups and its wide spread use can drastically reduce the need for conventional curettage.

Table 8: TVS vs HPE (Endometrial hyperplasia)

\begin{tabular}{lccc}
\hline Study & Year & Sensitivity & Specificity \\
Barman et al & 2014 & $43.7 \%$ & $95.6 \%$ \\
Choudhary et al & 2015 & $81 \%$ & $92 \%$ \\
Present study & 2018 & $100 \%$ & $100 \%$ \\
\hline
\end{tabular}

In the present study the sensitivity and specificity of TVS for hyperplasia was $100 \%$ which is comparable to findings of Chaudhary et al. i.e sensitivity of $81 \%$ \& specificity of $92 \%$. Barman et al. observed the sensitivity of TVS was $43.7 \%$ which was very less as compared to present study but their specificity was 95.6\%. k (kappa) statistics between TVS and histopathology showed fair agreement but $\mathrm{k}$ statistics between hysteroscopy and histopathology report had good agreement. Moreover majority (78.9\%) perimenopausal women in the present study had AUB with anovulatory cycles resulting in hyperestrogenic state leading to heavy menstrual bleeding.

Table 9: TVS vs HPE (Endometrial polyp)

\begin{tabular}{lccc}
\hline Study & Year & Sensitivity & Specificity \\
$\begin{array}{l}\text { Tandulwadkar et } \\
\text { al }\end{array}$ & 2009 & $71.4 \%$ & $96.3 \%$ \\
Vitner et al & 2013 & $44.8 \%$ & $81.8 \%$ \\
Present study & 2018 & $84.6 \%$ & $100 \%$ \\
\hline
\end{tabular}

In the present study specificity of TVS for detection of endometrial polyp was $100 \%$ while specificity observed by Tandulwadkar et al. and Vitner et al. was $96.3 \%$ and $81.8 \%$ respectively which is comparable to the present study. On the other hand sensitivity observed by Tandulwadkar et al. and Vitner et al. was $71.8 \%$ and $44.8 \%$ respectively which is markedly low as compared to the present study i.e $84.6 \%$.

Table 10: Hysteroscopy vs HPE (Endometrial hyperplasia)

\begin{tabular}{lccc}
\hline Study & Year & Sensitivity & Specificity \\
Shukla et al & 2012 & $100 \%$ & $98.04 \%$ \\
Barman et al & 2014 & $50 \%$ & $95.7 \%$ \\
Present study & 2018 & $100 \%$ & $96 \%$ \\
\hline
\end{tabular}


In our study sensitivity and specificity of hysteroscopy turned out to be $100 \%$ and $96 \%$ respectively as compared to TVS i.e $100 \%$ and $100 \%$ respectively. In a study by Nazim F (2013) diagnostic accuracy of TVS in identifying endometrial hyperplasia using histopathology as gold standard was $75.6 \%$. Barman et al. observed that on hysteroscopy $16.47 \%$ had hyperplastic endometrium and histopathology report confirmed hyperplastic endometrium in $35.71 \%$. Thus in experienced hands TVS has slightly better diagnostic accuracy in diagnosing endometrial hyperplasia as compared to hysteroscopy probably due to lack of specific diagnostic criteria.

Table 11: Hysteroscopy vs HPE (Endometrial polyp)

\begin{tabular}{lccc}
\hline Study & Year & Sensitivity & Specificity \\
Vitner et al & 2013 & $65.5 \%$ & $89.6 \%$ \\
Barman et al & 2017 & $71.4 \%$ & $100 \%$ \\
Present study & 2018 & $100 \%$ & $97.5 \%$ \\
\hline
\end{tabular}

In present study specificity of Hysteroscopy for endometrial polyp was $97.5 \%$. Vitner et al and Barman et al. documented specificity $89.6 \%$ and $100 \%$ respectively which correlates well with the present study. In our study sensitivity of Hysteroscopy for endometrial polyp is relatively high i.e $100 \%$ as compared to sensitivity $65.5 \%$ observed by Vitner et al. and $71.4 \%$ by Barman et al. In a systematic review by Forquhar $\mathrm{C}$ et al. there was a narrower range of sensitivity (90-97\%) but relatively wide range of specificity (62-93\%) for hysteroscopy to detect endometrial lesions in AUB. In our study hysteroscopy has slightly better diagnostic accuracy than TVS in detecting endometrial polyps which is consistant with the existing literature.

\section{Conclusion}

Abnormal uterine bleeding is a problem which women in perimenopausal and postmenopausal period frequently encounter. It has a negative impact on the quality of life and many woman end up undergoing hysterectomies. Management of AUB requires a correct diagnosis. Many modalities which help in the correct diagnosis are available.

TVS is an important modality for evaluating the patient of AUB. It is quick, simple, painless, least invasive, less expensive and readily available procedure and does not need full bladder like TAS. TVS can be the most cost effective initial test in women with abnormal uterine bleeding especially in perimenopausal age group but its ability for screening the lesions in the endometrial cavity is limited. In addition hysteroscopy has a better diagnostic accuracy as it provides the option of see and treat which is recommended for peri and post menopausal women with AUB. Though hysteroscopy showed better correlation with endometrial histopathology but endometrial hyperplasia was better diagnosed with TVS in the present study. The intracavitory lesions i.e endometrial polyps is better diagnosed on hysteroscopy. Also, it not only allows direct visual observation of pathology but also provides a means to sample the site, most likely to yield positive results. Hence it should be made an essential part of diagnostic workup of abnormal uterine bleeding.

\section{Source of Funding}

None.

\section{Conflict of Interest}

The author(s) declare(s) that there is no conflict of interest.

\section{References}

1. Indman PD. Abnormal uterine bleeding. Accuracy of vaginal probe ultrasound in predicting abnormal hysteroscopic findings. Reprod Med. 1995;40:545-8.

2. Mencaglia L, Perino A, Hamou J. Hysteroscopy in perimenopausal and postmenopausal women with abnormal uterine bleeding. J Reprod Med. 1987;32(8):577-82.

3. O\&apos;connor V. Heavy menstrual loss: Part 1. Is it really heavy loss? Med Today. 2003;4(4):51-9.

4. Garg P, Yadav S. Comparison of transvaginal ultrasonography and hysteroscopy in the evaluation of peri and postmenopausal bleeding. $\quad J$ Evol Med Dent Sci. 2016;5(21):1133-6. doi:10.14260/jemds/2016/263.

5. Howkins B, Shaw's. Shaw's Textbook of Gynaecology: Perimenopause, Menopause, Premature Menopause and Postmenopausal bleeding 16(e). New Delhi: Elsevier; 2015.

6. Sharma A, Dogra Y. Trends of AUB in tertiary centre of Shimla hills. J Mid-life Health. 2013;4(1):67. ब01:10.4103/09/6- 1800109648 .

7. Özdemir S, Çelik Ç, Gezginç K, Kıreşi D, Esen H. Evaluation of endometrial thickness with transvaginal ultrasonography and histopathology in premenopausal women with abnormal vaginal bleeding. Arch Gynecol Obstet. 2010;282(4):395-9. d01:10.1007/s00404-009-1290-y

8. Hoffman LB, Schorge OJ, Bradshaw DK, Halvorson ML, Schaffer IJ, Corton MM. Abnormal Uterine Bleeding. In: Williams gynaecology. McGraw Hill Education; 2016. p. 180-201.

9. Sarvi F, Alleyassin A, Aghahosseini M, Ghasemi M, Gity S. Hysteroscopy: A necessary method for detecting uterine pathologies in post-menopausal women with abnormal uterine bleeding or increased endometrial thickness. J Turk Soc Obstet Gynecol. 2016;13(4):183-8. d01:10.4274/tjod.66674.

10. Dasgupta S, Dasgupta S, Sharma PP, Mukherjee A, Ghosh TK. Abnormal Bleeding in Perimenopausal Age: Diagnostic options and accuracy. J Obstet Gynaecol Res. 2011;61(2):189-94.

11. Long CA. Evaluation of patients with abnormal uterine bleeding. Am J Obstet Gynecol. 1996;175:784-6.

12. Veena BT, Shivalingaiah N. Role of transvaginal sonography and diagnostic hysteroscopy in abnormal uterine bleeding. J Clin Diagn Res. 2014;8(12):6-8.

13. Aslam M, Ijaz L, Tariq S, Shafqat K, Meher-Un-Nisa, Ashraf R. Comparison of transvaginal sonography and saline contrast sonohysterography in women with abnormal uterine bleeding: correlation with hysteroscopy and histopathology. Int J Health Sci. 2007;1(1):17-24.

14. Howard JW, John RA. Operative Hysteroscopy. In: TeLinde's Operative Gynecology. New York: Wolters Kluwer; 2015. p. 307-36.

15. Long CA. Evaluation of patients with abnormal uterine bleeding. Am J Obstet Gynecol. 1996;175:784-6.

16. Barman SC, Bardhan J, Roy S, Sark N. Comparative evaluation of Transvaginal sonography and Diagnostic Hysteroscopy in abnormal uterine bleeding in perimenopausal age with their histopathological correlation. Sch J App Med Sci. 2017;5(3B):838-43. 


\section{Author biography}

Surbhi Sharma, Senior Resident

Anoop Sharma, Associate Professor
Cite this article: Sharma S, Sharma A. To compare the diagnostic accuracy of hysteroscopy with transvaginal sonography in detection of endometrial polyp and endometrial hyperplasia in peri and

postmenopausal women with abnormal uterine bleeding. Indian $J$

Obstet Gynecol Res 2020;7(4):498-503. 